Journal of Animal and Veterinary Advances 11 (10): 1578-1582, 2012

ISSN: $1680-5593$

(C) Medwell Journals, 2012

\title{
Prevalence of Coccidial Infection in Domestic Geese in Eastern China
}

\author{
J.J. Xu, S.S. Wang, D.D. Liu, L.Q. Cao, Y. Li and J.P. Tao \\ Key Lab for Avian Preventive Medicine, Ministry of Education, Yangzhou University, \\ 225009 Yangzhou, Jiangsu Province, P.R. China
}

\begin{abstract}
Coccidiosis causes diarrhoea, dehydration and death in geese. Eastern China is a large goose-raising area in China but the coccidial infection status in geese in this region has not been reported as so far. To understand Coccidia species and infection rate, fecal samples were collected from 146 randomly selected clinically healthy domestic goose populations between August 2010 and July 2011. Oocysts were separated by a floatation technique using saturated saline. Coccidia species was identified by examining morphological features of the sporulated oocysts and further verified through animal regression test. The results showed that coccidian oocysts were detected in $87.67 \%$ of the goose population. Eight different species of the Eimeriidae family were identified, namely $T$. parvula Koltan $(90.63 \%)$, E. hermani Farr $(76.56 \%)$, E. stigmosa Klimes (48.44\%), E. nocens Koltan (35.94\%), E. fulva Farr (15.63\%), E. anseris Koltan (9.38\%), E. farri Hanson, Levine and Ivens (4.69\%) and I. anseris Koltan (4.69\%). Among them, the first three species were most prevalent. In addition, $87.50 \%$ of the farms had at least two commensal Coccidia species, indicating concurrent infection existed widely in geese. The analysis of coccidial infection with age revealed that the infection mainly occurred in geese older than 30 days and the infection rate increased with ages. In summary, the results suggest that the coccidial infection was common in domestic geese in eastern China and measures for prevention and treatment of coccidiosis were needed for this area.
\end{abstract}

Key words: Coccidial infection, regression, oocytes, goose, prevalence, Eastern China

\section{INTRODUCTION}

Goose coccidiosis, a parasitic protozoiasis is caused by a variety of coccidia in domestic and wild geese. It is distributed worldwide and is especially common in domestic geese in Europe and North America (Hanson et al., 1957). Generally, it leads to diarrhoea, dehydration and death in geese. As this disease had been thought to be less harmful all the time, few researches which are mainly about investigation and identification of Coccidia species (Soulsby, 1986) have been conducted to study goose coccidiosis. The disease has two distinct types, namely renal coccidiosis and intestinal coccidiosis. Renal coccidiosis is primarily caused by $E$. truncate and has high morbidity and mortality in infected geese.

Intestinal coccidiosis is caused by many Coccidia species such as $E$. anseris, $E$. nocens, $E$. stigmosa, $E$. kotlani, T. parvula, E. fulva, $E$. hermani, $E$. magnalabia and E. striata (Gajadhar et al., 1983a; Levine, 1985). In addition, Coccidia species and infection rate have regional differences in geese (Xie et al., 1986; Li and Fu, 1994; Arslan et al., 2002). The goose industry in China has been developing rapidly in recent years with the raising practice shifting from scattered, back yard style to large- scale intensive barn raising and the number of geese raised increasing sharply year by year. In 2010, the slaughtered geese in China accounted for $93.5 \%$ of those in the world and $99.2 \%$ of those in Asia while the number of slaughtered geese in eastern China accounted for $55 \%$ of those in China (Wang, 2011). The present intensive feeding provides favorable conditions for the occurrence and spread of goose coccidiosis. Currently, goose coccidiosis occurs occasionally in China and causes economic losses in goose industry. After goose coccidiosis was first reported in Jiangsu province (Fu et al., 1986), China, Coccidia species in geese were preliminarily surveyed in Guangdong (Xie et al., 1986) and Anhui province ( $\mathrm{Li}$ and $\mathrm{Fu}, 1994$ ) based on morphological features of sporulated oocysts.

Due to morphological similarity of sporulated oocysts between some Coccidial species, accurate identification cannot be achieved merely on the basis of morphology and other discrimination methods should also be applied (Gajadhar et al., 1983a; Levine, 1985). Prior to the present investigation, there had been no survey on the prevalence of Coccidial infection in geese in eastern China. Therefore, the aim of the present study was to accurately investigate coccidial infection in geese in this

Corresponding Author: J.P. Tao, Key Lab for Avian Preventive Medicine, Ministry of Education, Veterinary College, Yangzhou University, No. 12 Wenhui Road, 225009 Yangzhou, Jiangsu Province, P.R. China 
region and to provide a scientific reference for better control of coccidiosis. Researchers identified prevalent Coccidia species and the infection status in goose farms by observing morphological features of oocysts in feces. Animal regression test was also carried to verify the results.

\section{MATERIALS AND METHODS}

Sampling area: The investigation was performed in East China. This area has mild weather, moderate rainfall, clear-cut seasonal changes and an average air temperature of $13-16^{\circ} \mathrm{C}$. Its animal husbandry holds an important position in China with the output of livestock and livestock products topping in the country. The amount of slaughtered geese was 430 million (about $55 \%$ of that in China) in 2010 and is still increasing year by year.

Sample collection: Fecal samples were collected from 146 randomly selected apparently healthy domestic goose populations in seven main geese rearing administrative regions in eastern China between August 2010 and July 2011. The samples, each of 100-200 g were collected at four surrounding points and one central point of each goose house and stroed at $4^{\circ} \mathrm{C}$ before examination. All these geese were stocked on the floor or reared in pens on the floor. No anti-coccidiosis drug was used for prevention and treatment of coccidiosis.

Separation and sporulation of oocysts: Coccidian Oocysts Per Gram (OPG) of fecal samples were determined by a modified McMaster Technique. Oocysts were then separated using saturated saline floatation technique as previously described by Li and Fu (1994). Fecal samples were mixed well with water by stirring. After fecal dregs were removed by straining the blend through copper mesh (60 mesh) and nylon sieve (260 mesh) in turn, the filtrate was collected and settled freely. Following removal of the supernatant, the pellet was resuspended in saturated sodium chloride solution to float oocysts. Then, the oocysts were sporulated by incubation in $2.5 \%(\mathrm{w} / \mathrm{t})$ aqueous potassium dichromate solution at $29^{\circ} \mathrm{C}$ for 5 days.

Preliminary identification of Coccidia species: The sporulated oocysts were dropped on a glass slide and covered with a cover slip. Their morphological features were observed under a microscope at a magnification of $400 \mathrm{x}$. Twenty oocysts were measured to determine the average size of oocysts and sporocysts. The coccidian oocysts were identified based on their sizes and morphological characteristics as previously described (Hanson et al., 1957; Levine, 1985).

Animal regression test: The sporulated oocysts of each fecal sample were orally inoculated into four, 20 days old coccidia free goslings. They were kept in coccidia-free environment disinfected by flame and fed on diets not containing any anti-coccidiosis drug. The water was boiled for $10 \mathrm{~min}$ and cooled before drinking. After 4-14 days post inoculation, their feces were collected every $12 \mathrm{~h}$. The oocysts were isolated and sporulated. Coccidia species in each sample were identified according to prepatent period of oocysts and morphological characteristics of the sporulated oocysts.

Statistical analysis: Differences in prevalence between different age groups of geese as well as different regions were evaluated using a $\chi^{2}$-test in SPSS for Windows (Release 17.0 standard Version, SPSS Inc., Chicago, IL) and a value of $\mathrm{p}<0.05$ was considered significant.

\section{RESULTS AND DISCUSSION}

Coccidia species in domestic geese in Eastern China: Eight different Coccidia species belonging to three genera of the Eimeriidae family were found in the fecal samples collected. Of the Eimeria genus, E. nocens Koltan (1933), E. fulva Farr (1953), E. hermani Farr (1953), E. anseris Koltan (1932), E. farri Hanson et al. (1957) and E. stigmosa Klimes (1963) were identified. I. anseris Koltan (1932) belonging to the Isospora genus and T. parvula Koltan (1933) belonging to the Tyzzeria genus were also found. Morphological features of these Coccidia species are shown in Fig. 1. The morphological feature and prepatent period of each species obtainted by animal regression test were described.

E. nocens: The shape of sporulated oocysts is ovoid but fattened at the micropylar end, 29-34×19-22.5 $\mu \mathrm{m}$ with a mean of $32.23 \pm 2.02 \times 20.01 \pm 3.10 \mu \mathrm{m}$. The oocyst wall is smooth and consists of two layers, the outer layer is pale yellow and the inner is colorless. The micropyle appears to be in the inner wall and is covered by the outer wall. The sporocysts are broadly ellipsoidal, $12.5-15 \times 10-12.5 \mu \mathrm{m}$ with a mean of $13.64 \pm 1.30 \times 10.23 \pm 0.75 \mu \mathrm{m}$. The oocyst polar granule and oocyst residuum are absent, part of the oocyst wall forms one or more roundish protuberances just below the micropyle. A small Stieda body is present with sporocyst residuum filling the space between sporozoites. The prepatent period is $228 \mathrm{~h}$. 

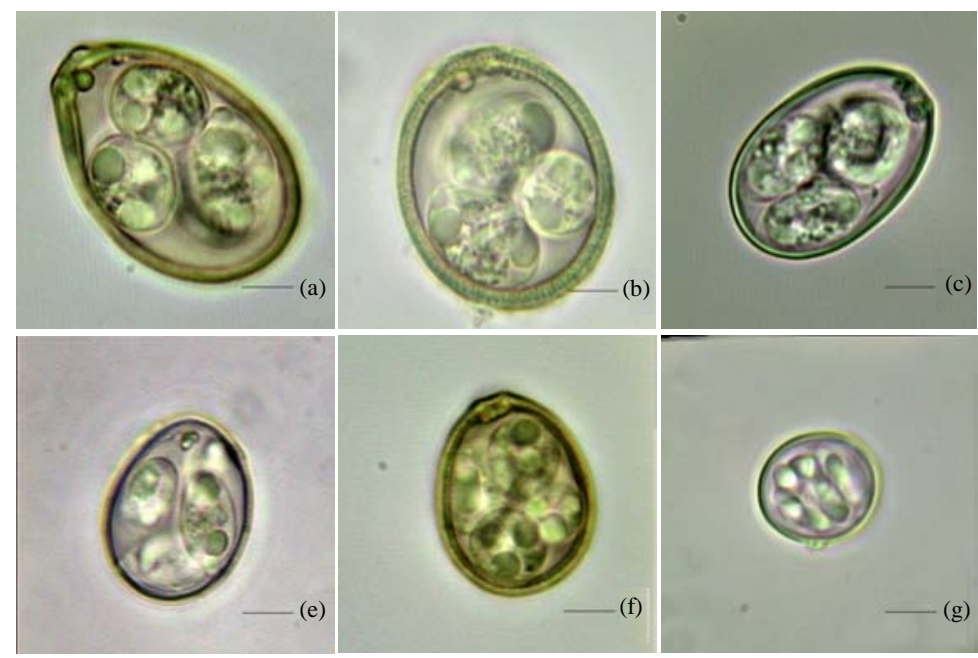
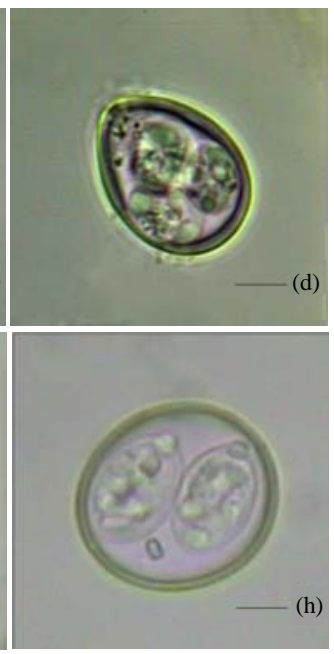

Fig. 1: Sporulated oosysts of eight Eimeriidae species; a) E. nocens Koltan; b) E. fulva Farr; c) E. hermani Farr; d) E. anseris Koltan; e) E. farri Hanson, Levine and Ivens; f) E. stigmosa Klimes; g) T. parvula Koltan; h) I. anseris Koltan. The actual size of each sporulated oosyst was described in the text. Scale bars $=5 \mu \mathrm{m}$

E. fulva: The oocysts are broadly ovoid and slightly flattened at the narrow micropylar end, $29.5-33 \times 20-23 \mu \mathrm{m}$ with a mean of $31.22 \pm 1.86 \times 21.7 \pm 2.79 \mu \mathrm{m}$. The oocyst wall is composed of two layers. The outer layer is brownish yellow, pitted and transversely striated. The inner layer is smooth and colorless. The sporocysts are ovoid, $10-15 \times 8.75-12.5 \mu \mathrm{m}$ with a mean of $12.48 \pm 0.81 \times 10.19 \pm 0.93 \mu \mathrm{m}$. There is a large polar granule near the micropyle. The oocyst residuum is absent. Sporocyst residuum and a prominent Stieda body are present. The prepatent period is $180 \mathrm{~h}$.

E. hermani: The oocysts are ovoid, fattened and narrowed at the micropylar end, $19-27 \times 10-22 \mu \mathrm{m}$ with a mean of $22.39 \pm 1.56 \times 16.14 \pm 1.06 \mu \mathrm{m}$. The oocyst wall is composed of two layers which are smooth and colorless. There is a nodular protuberance at each side of the micropyle. The sporocysts are ovoid, 7.5-2.5 $\times 5-11.5 \mu \mathrm{m}$ with a mean of $10.75 \pm 1.78 \times 7.81 \pm 1.89 \mu \mathrm{m}$. The oocyst polar granule and oocyst residuum are absent. Sporocyst residuum and Stieda body are present. The prepatent period is $108 \mathrm{~h}$.

E. anseris: The oocysts are pear-shaped with a micropyle at the truncate end, $18-23 \times 12.5-17.54 \mu \mathrm{m}$ with a mean of $21.89 \pm 1.41 \times 14.58 \pm 1.22 \mu \mathrm{m}$. The oocyst wall is smooth, colorless, composed of a single laye and incised sharply to form a plate or shelf across the micropyle. The sporocysts are ovoid and almost completely fill the oocyst, 7.5-10×5-6.25 $\mu \mathrm{m}$ with a mean of $9.56 \pm 0.93 \times 5.06 \pm 0.49 \mu \mathrm{m}$. The oocyst polar granule is absent, oocyst residuum is a mass of amorphous material just beneath the micropyle and forms a seal. The sporocyst residuum is granular and stieda body is not obvious. The prepatent period is $156 \mathrm{~h}$.

E. farri: The oocysts are ovoid to ellipsoidal, $20-22 \times 15-17.5 \mu \mathrm{m}$ with a mean of $20.40 \pm 0.79 \times$ $16.67 \pm 0.93 \mu \mathrm{m}$. The oocyst wall is smooth, colorless or pale yellow, composed of a single layer. The micropyle is absent. The sporocysts are long ovoid, 6.5-13×4.5-5.25 $\mu \mathrm{m}$ with a mean of $10.42 \pm 0.36 \times 4.98 \pm 0.32 \mu \mathrm{m}$. There is no oocyst polar granule with oocyst residuum present. A sporocyst residuum and a stieda body are present. The prepatent period is $120 \mathrm{~h}$.

E. stigmosa: The shape of sporulated oocysts is broadly ovoid, a little narrow at the micropyle end, $17-27 \times 10-22 \mu \mathrm{m}$ with a mean of $21.25 \pm 1.26 \times 16.84 \pm 1.11 \mu \mathrm{m}$. The oocyst wall consists of a single layer which is punctate, radially striated and brown. The sporocysts are ovoid, $11.25-15 \times 7.5-12.5 \mu \mathrm{m}$ with a mean of $12.50 \pm 0.81 \times 10.17 \pm 1.00 \mu \mathrm{m}$ with a sporocyst residuum and a Stieda body are present. There are one or two oocyst polar granules, oocyst residuum is absent. The prepatent period is $108 \mathrm{~h}$.

Isospora anseris: The oocysts are ellipsoidal, $21-23 \times 22-25 \mu \mathrm{m}$ with mean of $21.55 \pm 1.21 \times 23.61 \pm 1.22 \mu \mathrm{m}$. The oocyst wall is smooth, colorless, composed of a single layer. The sporocysts are ovoid, 15-17.3× 11.3-13.7 $\mu \mathrm{m}$ with a mean of $15.5 \times 12.5 \mu \mathrm{m}$. There are two 
sporocysts in a sporulated oocyst which contain four sporozoites in each sporocysts. The oocyst residuum and micropyle are absent. A polar granule, a Stieda body and sporocyst residuum are present. The prepatent period is $120 \mathrm{~h}$.

T. parvula: The oocysts are subspherical to spherical, $6-15 \times 4-13 \mu \mathrm{m}$ with a mean of $11.55 \pm 1.21 \times 9.61 \pm 1.22 \mu \mathrm{m}$. The oocyst wall is smooth, colorless, composed of a single layer. The micropyle is absent. The sporulated oocysts contain eight banana-shaped sporozoites surrounding the residuum. The prepatent period is $120 \mathrm{~h}$.

Coccidial infection in domestic geese in Eastern China: Coccidial infection, mainly concurrent infection was found in $87.67 \%(128 / 146)$ of the surveyed goose populations, ranged from $82.35-90 \%$ in seven locations. However, there were no statistically significant difference in prevalence among seven different regions ( $p>0.05$ ) (Table 1). Two Coccidia species were commensal in $39.06 \%$ of the infected goose populations and three Coccidia species were commensal in $28.13 \%$ of the infected goose populations. Furthermore, $87.50 \%$ of the infected goose populations had more than two commensal Coccidial species (Table 2). In addition, the positive rate of coccidial infection increased with aging in geese. The positive rate of coccidial infection was $12.5 \%$ at the age of $1-30$ days then rose dramatically at the age of 30-60 days and $60-90$ days and reached $100 \%$ at the age of older than 90 days. The positive rate at the age of 1-30 days was significantly lower compared to other age groups $(\mathrm{p}<0.05)$ (Table 3). The differences in $O P G$ were not significant among different age groups $(\mathrm{p}>0.05)$ (Table 3).

Table 1: Prevalence of coccidial infection in geese in different administrative regions in Eastem China

\begin{tabular}{|c|c|c|c|}
\hline Geographical locations & Examined No. & Positive No. & Prevalence $(\%)$ \\
\hline Region A & 18 & 16 & 88.89 \\
\hline Region B & 15 & 13 & 86.67 \\
\hline Region C & 20 & 18 & 90.00 \\
\hline Region D & 28 & 25 & 89.29 \\
\hline Region $\mathrm{E}$ & 26 & 23 & 88.46 \\
\hline Region $\mathrm{F}$ & 22 & 19 & 86.36 \\
\hline Region $\mathrm{G}$ & 17 & 14 & 82.35 \\
\hline Total & 146 & 128 & 87.67 \\
\hline
\end{tabular}

Table 2: Prevalence of commensal Coccidia species in the 128 infected goose populations

\begin{tabular}{lcc}
\hline \multicolumn{2}{c}{ goose populations } & \\
Number of commensal & & Prevalence (\%) \\
\hline 1 & Positive No. & 12.50 \\
2 & 16 & 39.06 \\
3 & 50 & 28.13 \\
4 & 36 & 10.94 \\
5 & 14 & 6.25 \\
6 & 8 & 3.13 \\
\hline
\end{tabular}

Infection rates of different Coccidia species in Eastern China: In Eastern China, $T$. parvula Koltan and $E$. hermani Farr were the most prevalent species in the coccidia-positive goose populations followed by E. stigmosa Klimes, E. nocens Koltan and E. fulva Farr. Species of E. anseris Koltan, E. farri Hanson, Levine and Ivens and $I$. anseris Koltan had lower infection rates in the positive goose populations. The infection rates of these Coccidia species are shown in Table 4.

Goose coccidiosis has drawn less attention compared to bacterial and viral diseases in geese. Here we reported the Coccidia species and infection rates in geese in Eastern China. Fecal samples for the present study were collected from geese of different ages in the rainy season (mainly in June and July) when animals are most susceptible to coccidial infection (Pellerdy, 1974; Levine, 1985). Therefore, the investigation results basically reflect the status of coccidial infection in the region. Differences in Coccidia species and infection rates between seasons were not analyzed due to the limitation of experimental conditions.

In the present investigation, $T$. parvula Koltan, $E$. hermani Farr, E. stigmosa Klimes, E. nocens Koltan, E. fulva Farr, E. anseris Koltan, E. farri Hanson, Levine and Ivens and $I$. anseris Koltan, all belonging to the Eimeriidae family were found in geese. The former three Coccidia species had higher infection rates. These results are similar to those reported in France and Turkey (Arslan et al., 2002). Additionally, the goose Coccidia species isolated in Eastern China were basically the same as those isolated in other parts of China but the number of goose Coccidia species was slightly more than that in southern China (Xie et al., 1986) and orther regions (Li and Fu,1994). The observation of oocyst morphology

Table 3: Prevalence and intensity of coccidial infection in the goose populations of different ages

\begin{tabular}{|c|c|c|c|c|}
\hline \multirow[b]{2}{*}{ Age (days) } & \multicolumn{2}{|l|}{ Number } & \multirow[b]{2}{*}{ Prevalence (\%) } & \multirow{2}{*}{$\begin{array}{l}\text { Average oocyst } \\
\text { per gram of faeces } \\
\text { of postive samples }\end{array}$} \\
\hline & Examined & Positive & & \\
\hline $1-30$ & 16 & 2 & 12.50 & 5200 \\
\hline $30-60$ & 40 & 38 & 95.00 & 4800 \\
\hline $60-90$ & 54 & 52 & 96.30 & 5000 \\
\hline $90-360$ & 36 & 36 & 100.00 & 4900 \\
\hline
\end{tabular}

Table 4: Coccidia species identified and their prevalence in the 128 infected goose populations

\begin{tabular}{lcc}
\hline Species & Positive No. & Prevalence (\%) \\
\hline E. nocens Koltan & 46 & 35.94 \\
E. fulva Farr & 20 & 15.63 \\
E. hermani Farr & 98 & 76.56 \\
E. anseris Koltan & 12 & 9.38 \\
E. farri Hanson, Levine and Ivens & 6 & 4.69 \\
E. stigmosa Klimes & 62 & 48.44 \\
I. anseris Koltan & 6 & 4.69 \\
T. parvula Koltan & 116 & 90.63 \\
\hline
\end{tabular}


is an important but not a reliable way for identification of Coccidia species (Levine, 1985) because some sporulated oocysts have very similar features. For more accurate survey researchers performed both morphological examination and animal regression test to distinguish different Coccidia species according to their morphological characteristics and prepatent period. This may interpret why more Coccidia species were isolated in eastern China than other regions of China. Notably, renal coccidiosis caused by E. truncata was not found in Eastern China, Southern China and other regions. This Coccidia species mostly lives in wild geese (Gajadhar et al., 1983b) and has low infection rate in domestic geese in China.

\section{CONCLUSION}

The positive rate of coccidial infection reached $87.67 \%$ in the domestic goose populations in eastern China. Most goose populations suffered from mixed infection. Some goose populations showed diarrhea and dehydration occasionally as described by farmers (personal communications). These data indicate that the coccidial infection is prevalent in geese in this region. At present, the majority of field veterinarians and farmers in China do not have enough knowledge about the comprehensive prevention and control of goose coccidiosis. Moreover, no effective monitoring measure is available for this disease. Thus, coccidial infection occurrs frequently, resulting in serious economic loss. In order to effectively control coccidiosis, knowledge about prevention and treatment of coccidiosis should be publicized and a scientific control system should also be established. In summary, the present investigation revealed that the coccidial infection is very common in domestic geese in Eastern China. The study suggested that preventive measures need be taken and effective drugs should be selected for the prevention and treatment of coccidiosis in greese.

\section{ACKNOWLEDGEMENTS}

This study was financially supported by the Project Funded by the Priority Academic Program Development of Jiangsu Higher Education Institutions and the Program for Changjiang Scholars and Innovative Research Team in University (Grant No.: IRT0978).

\section{REFERENCES}

Arslan, M.O., Y. Gicik and K. Ozcan, 2002. The frequency of Eimeriidae species in the domestic geese in Kars province of Turkey. Acta Protozool., 41: 353-357.

Fu, A.Q., M.C. Lin, H.F. Tian and K.H. Jiao, 1986. Survey on Coccidia species in domestic geese. Chin. J. Vet. Sci. Tech., 2: 23-24.

Gajadhar, A.A., G. Wobeser and P.H.G. Stockdale, 1983a. Coccidia of domestic and wild waterfowl (Anseriformes). Can. J. Zoo., 61: 1-24.

Gajadhar, A.A., R.J. Cawthorn, G.A. Wobeser and P.H.G. Stockdale, 1983b. Prevalence of renal coccidia in wild waterfowl in Saskatchewan. Can. J. Zoo., 61: 2631-2633.

Hanson, H.C., N.D. Levine and V. Ivens, 1957. Coccidia (Protozoa: Eimeriidae) of North American wild geese and swans. Can. J. Zoo., 35: 715-733.

Levine, N.D., 1985. Veterinary Protozoology. Iowa State University Press, Ames, IA, pp: 195-211.

Li, P.Y. and Y.H. Fu, 1994. Investigation on coccidia species in white geese in west Anhui. Shanghai J. Anim. Husb. Vet. Med., 1: 36-37.

Pellerdy, L.P., 1974. Coccidia and Coccidiosis. 2nd Edn., Parey, Berlin, ISBN: 9783489733171 , Pages: 959.

Soulsby, E.J.L., 1986. Helminths, Arthropods and Protozoa of Domesticated Animals 7th Edn., Lea and Febiger, London, ISBN: 978-0812107807, Pages: 809.

Wang, L.Y., 2011. Profiles of goose products and market demand. Chin. Livestock Poul. Breeding, 7: 130-133.

Xie, M.Q., F.Q. Zhang, Y.M. Lu, L.N. Wen, J.F. Zhang and H.X. Wu, 1986. Priliminary survey on coccidia species in Guangdong Provice. Chin. J. Vet. Med., 12: $7-10$. 